\title{
Acute inflammatory response in the subcutaneous versus periprosthethic space after incisional hernia repair: an original article
}

\author{
Rosalia Patti, Anna Maria Caruso, Paolo Aiello, Giuseppe Livio Angelo, Salvatore Buscemi and Gaetano Di Vita*
}

\begin{abstract}
Background: The acute inflammatory response following mesh implantation has been often evaluated in vitro and in animal models. The aim of this study was to evaluate the acute inflammatory response near the prosthesis in human by analysing some inflammatory indicators.

Methods: We used a cohort of twelve male patients affected by midline incisional hernia, who were admitted for surgical mesh repair. A suction drain was placed between the mesh and rectal muscles whereas, the other one was placed between the subcutaneous tissue and the oblique external sheath. The acute inflammatory response was analyzed by measuring the production of interleukin [IL]-1, IL-10, IL-1 ra, C-Reactive Protein (CRP), total proteins, albumin and $\mathrm{pH}$ in the drain fluids.

Results: The dynamics of CRP and ILs production resulted similar in both drainages. Comparing drain over mesh and subcutaneous drain at all times, IL-1 and CRP values always resulted significantly higher in the first one, whereas IL-1ra and IL-10 values were significantly higher in the last one. Total protein and albumin were similar in both drains at all time; only in the drain over mesh fluid, pH values resulted significantly reduced in the fourth post-operative day.
\end{abstract}

Conclusions: Our data showed that an acute inflammatory reaction is present in both sites examined. However, it was significantly higher in the space after mesh implantation.

Keywords: Cytokines, Drain fluid, Hernia repair, Inflammatory response, Prosthesis

\section{Background}

The use of a prostheses in hernia surgery of the abdominal wall has significantly reduced the incidence of recurrence. Therefore, some complications, such as seroma formation, chronic pain, feeling of foreign body, wound infection, abdominal wall stiffness and nerve entrapment complaints occur more frequently after mesh repair. They seem to be related to a higher inflammatory response to the prosthetic material [1].

The implantation of surgical biomaterials challenges the onset of a local inflammatory response syndrome, which is a non-systemic reaction to sterile infection (e.g., trauma, necrosis), microbiological infection, or a combination of

\footnotetext{
* Correspondence: divitagaetano@libero.it

Department of Surgical, Oncological and Stomatological Science, General Surgery Unit, University of Palermo, Via Liborio Giuffrè n 5, 90127 Palermo, Italy
}

both [2]. Mesh induced inflammation is linked to the foreign body granulation with alteration in the collagen composition [3]. Henceforth, it can be postulated that the level of inflammatory response is a major determinant of biocompatibility, and that addressing inflammation might reduce fibrosis around foreign body materials.

To date, acute inflammatory response following mesh implantation has often been evaluated in vitro and in the animal models through histologic and immunohistochemical studies [3-5]. In order to evaluate the precocious inflammatory response to mesh in vivo in humans, we chose to use a suitable model constituted by patients affected by a large median incisional hernia who underwent prosthetic hernia repair, using a sublay technique. This operation consists in a large dissection of both abdominal rectal muscles and their posterior sheath, in order to place the mesh, as well as a further dissection 
between subcutaneous tissue and sheath of the external oblique muscle [6].

The aim of this study was to evaluate, in the same patient, the acute inflammatory response in drain fluid produced near the prosthesis (DM) and in the subcutaneous space (DS) after prosthetic incisional hernia repair. For this reason, we evaluated some inflammatory indicators like cytokines (interleukins)[IL]-1, -10 and -1ra, C-Reactive Protein (CRP), total proteins, albumin and $\mathrm{pH}$.

\section{Methods}

The cohort of twelve male patients affected by midline incisional hernia with multiple hernial holes or with hernial defect of about $10 \mathrm{~cm}$ in size who, were admitted for surgical repair, were included in this study. We excluded patients ages $>70$ years, with co-morbidities like diabetes, hepatic cirrhosis, renal or heart failure, with infection or a potentially contaminated surgical field, and patients with necessity of a concomitant abdominal surgery.

All patients received an intravenous dose of 2 gr ceftadizime preoperatively that was administered two times daily for three days following surgery and low-molecular-weight heparin prophylaxis.

\section{Ethics}

All participants gave a written informed consent. The ethics committee "Comitato etico dell'Azienda Ospedaliera Universitaria Policlinico Paolo Giaccone dell'Università degli Studi di Palermo" granted the exemption of the study from requiring ethics approval.

The research has been carried out adhering to the STROBE guidelines for observational studies.

\section{Surgical procedure}

The operation starts with excision of the skin scar. The skin was separated from the surrounding tissue and wide undermining of the subcutaneous was done up to semilunar line. Excess sac was preserved. Medial edge of each rectus muscle was identified through palpation, and extreme medial edge of each rectus sheath was incised along its length to enter into the sub-muscular space.

This relatively bloodless plane could be developed easily to the lateral edges of the rectal muscle on each side. Dissection was stopped when an overlap of 5-6 cm to both lateral sides is reached. The vascular-nervous bundle of rectal muscle was identified to avoid damaging it during the preparation.

The posterior sheath of rectal muscle was secured with continuous sutures. A high density polypropylene mesh was placed between posterior sheath of rectal muscle and rectal muscle itself. The size of the mesh was $20 \times 20 \mathrm{~cm}$. Mesh was secured with 3-0 polypropylene stitches placed at the limits of dissection. A closed suction drain was placed over the mesh. In all cases both rectal muscles were closed to the median line and the anterior sheath was secured with separated stitches. Relaxing incision of the anterior rectal sheath were performed in all cases. Another closed suction drain was placed between the subcutaneous fat and oblique external sheath.

The wound drains were removed when the amount of drained fluid was less than $50 \mathrm{ml}$. The removal occurred in post-operative day (POD)- 4 in 7 cases, in POD-5 in 3 cases and in POD-7 in other two cases. Drainage fluids were cultured only if infection was suspected (notably wound edema, erythema, or serosanguinous discharge), although this was not required in any patient included in the study. Body temperature was monitored by means of axillary temperature measurement 6 hours after surgery and on POD-1, 2 and 7.

Postoperative pain was assessed by the patient on mobilization by means of a visual analogue scale ranging from 0 (no pain) to 10 (worst pain imaginable) at 6, 24, 48, and 168 hours. Patients discharged before these times were requested to record pain at home. An analgesic therapy (oral tramadol hydrochloride) was administered on demand.

\section{Wound fluid samples and assays}

Surgical wound fluids were assembled in closed sterile collection bags, which were replaced daily with new sterile bags under aseptic conditions. Wound fluids were collected on POD-1 until to POD-4. The amount of fluids collected for each patient was carefully recorded each time.

A sample of liquid was sent to the central laboratory of our department to determine $\mathrm{pH}$, total proteins, albumin and CRP. A sample of this liquid were centrifuged at $2000 \mathrm{r}$ for 10 minutes and stored at $-70^{\circ} \mathrm{C}$. Commercial enzyme-linked immunoadsorbant assay (ELISA) kits were used to determine the production of IL-10, -1 and -1ra (Euroclone, Wetherby, United Kingdom). The main test was a sandwich enzyme immune assay that uses a monoclonal antibody immobilized on a solid phase to capture antigen from the test specimen; peroxidase-conjugated monoclonal antibody was added to bind the antigens captured by the first antibody. At the time of the dosage, wound fluid samples were diluted where needed, and the assay protocol was performed by ELISA. The optical density for each well was determined using a microplate reader set at $450 \mathrm{~nm}$ with correction wavelength set at $540 \mathrm{~nm}$.

Cytokines, total proteins, albumin and CRP quantity produced over 24 hours values were obtained multiplying their concentration by the volume collected in 24 hours. This procedure proved to be an accurate method in evaluating cytokine secretion because their production rate per milliliter varies according either the different method used or the pathology studied. Furthermore, cytokine 
secretion may change over time showing different values at the beginning and at the end of the observation time.

\section{Statistical analysis}

All statistical analysis were performed using a statistical program (Graph Pad Instat Version 3.06 for Windows). Continous variable were given as mean and standard deviation. Unpaired $t$ test with Welch correction was used to compare data from the two groups of variables. The variance analysis was performed by ANOVA with Bonferroni correction.

\section{Results}

Age, ASA grade, diameter of hernial orifice, duration of operation, body mass index, and duration of hospital stay are shown in Table 1 . All patients had uncomplicated intraoperative and postoperative course.

Postoperative pain score values and analgesic consumption were higher in POD-1 and decreased in the following days. Body temperature peaking at 24 hours and returning to almost the same preoperative levels at 48 hours and no correlation was shown between temperature and markers of the inflammatory response (data not shown).

Clinical-instrumental controls up to a month after surgery showed no formation of seroma.

\section{Drain fluid}

The characteristics of the fluid collected in the two drainage pouches was shown in Figure 1. In both drainage pouches, fluid was more copious on POD-1 and decreased progressively afterward. Initially the fluid had bloody characteristics, becoming serum like after. The pattern of drain fluid production was similar in both drains decreasing significantly from the POD-1 to POD-4, although the amount of fluid was higher in DS at all times. However, these higher rates of secretion were not statistically significant at various time.

\section{Table 1 Demographic and clinical features of patients}

Gender (male) n

Age (years)

Mean \pm SD

$44.2 \pm 12.1$

ASA score

n

|-II

III-IV

9

4

BMI (Mean \pm SD)

$28 \pm 9.2$

Mean diameter of hernial orifice $(\mathrm{cm})$

$8.3 \pm 1.9$

Mean duration of operation (min)

$92 \pm 10.6$

$4.2 \pm 0.9$

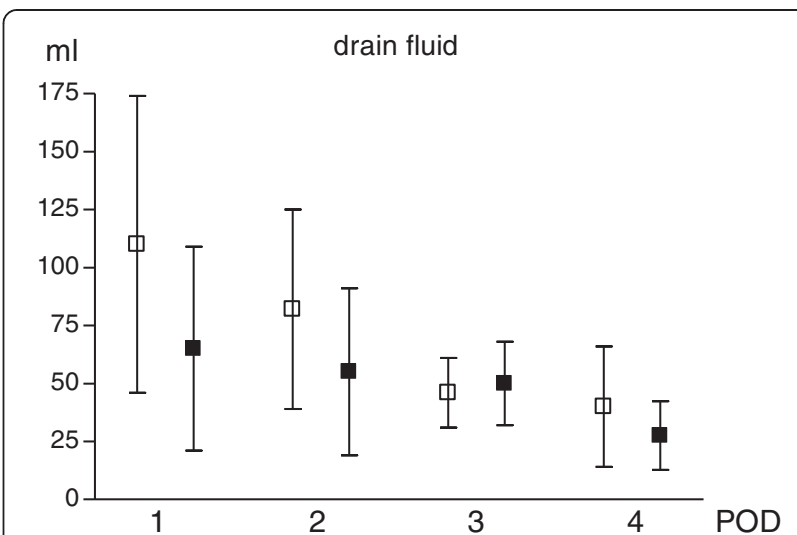

Figure 1 Drain fluid collected after surgery in the two drains. White square: DS; black square: DM Values are expressed $s$ mean \pm standard deviation. Unpaired t test with Welch correction was used. There are no significant differences among the two group for each assessment. The amount of drain fluid decreased significantly from POD-1 to POD-4 in both groups ( $p<0.01$ in DS; $p<0.05$ in DM).

\section{CRP, total protein, albumin and $\mathrm{pH}$}

The production of CRP showed a similar pattern in the fluid of both drains. CRP values resulted significantly increased in POD-2 if compared with POD-1 and reduced in POD-4. When comparing the two groups simultaneously, no significant differences were detected (Figure 2).

The amount of total protein and albumin resulted similar at all times and in comparison between DS and DM (data not shown).

$\mathrm{PH}$ values have not shown significant modifications in the DS. In the DM fluid $\mathrm{pH}$ values resulted significantly

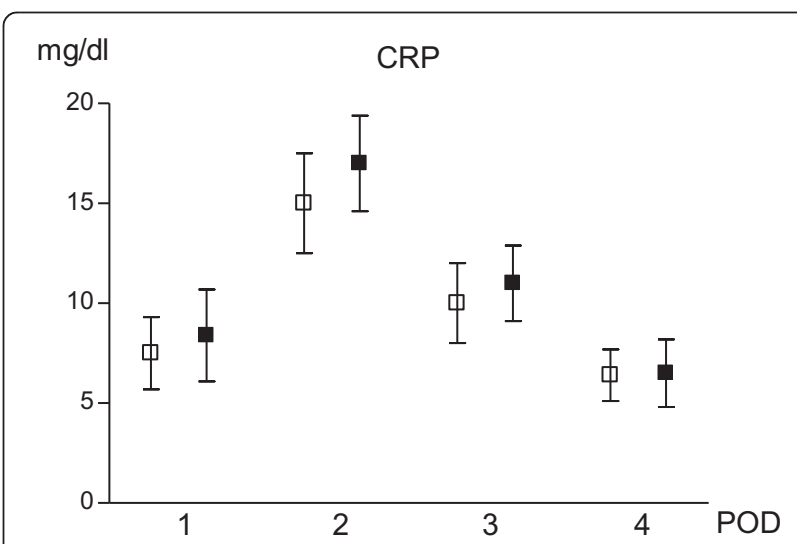

Figure 2 CRP modifications after surgery in two drains. White square: DS; black square: DM Values are expressed as mean \pm standard deviation. Unpaired t test with Welch correction was used. There are no significant differences among the two group for each assessment. Significance in DS group: POD-1 vs POD-2 p <0.0001; POD-1 vs POD-3 $p<0.01$; POD-1 vs POD-4 $p=$ n.s. Significance in DM group: POD-1 vs POD-2 $p<0.0001$; POD-1 vs POD-3 $p<0.01$; POD-1 vs POD-4 $p=$ n.s. 
reduced in POD-4 when compared to those detected in POD-1 ( $<<0.05)$ (Figure 3).

\section{Cytokines in drain fluid}

The dynamics of IL production resulted similar in both drainages (Figure 4).

In DS, no significant differences of IL-1 values were detected for all PODs. In DM, on the other hand, a significant reduction of IL-1 production value was reached in POD-3. Comparing DM with DS at all times, IL-1 values resulted significantly higher in DM (Figure 4a).

IL-1ra and IL-10 values in DM were similar in all PODs, whereas they resulted higher in POD-1 decreasing significantly starting from POD-2 in DS. Comparing DS and DM, both cytokines were always significantly higher in DS in POD-1, POD-2 and POD-3 (Figure 4b and c).

\section{Discussion}

Wound healing is a dynamic process that involves a coordinated umoral response of many cell types representing distinct tissue compartments and is fundamentally similar among tissue types. The inflammatory phase of wound healing is characterized by the infiltration of neutrophils, macrophages, and lymphocytes, which participate by releasing pro-inflammatory and anti-inflammatory cytokines, growth factor, ingesting foreign materials, increasing vascular permeability, and promoting fibroblast activity $[7,8]$. The presence of a foreign body as the mesh may alter the wound healing process [4]. Host reactions following implantation of biomaterials starts with blood/ materials interactions and with provisional matrix formation, constituted by plasma proteins [9]. The progression of events is characterized by the extravasation and

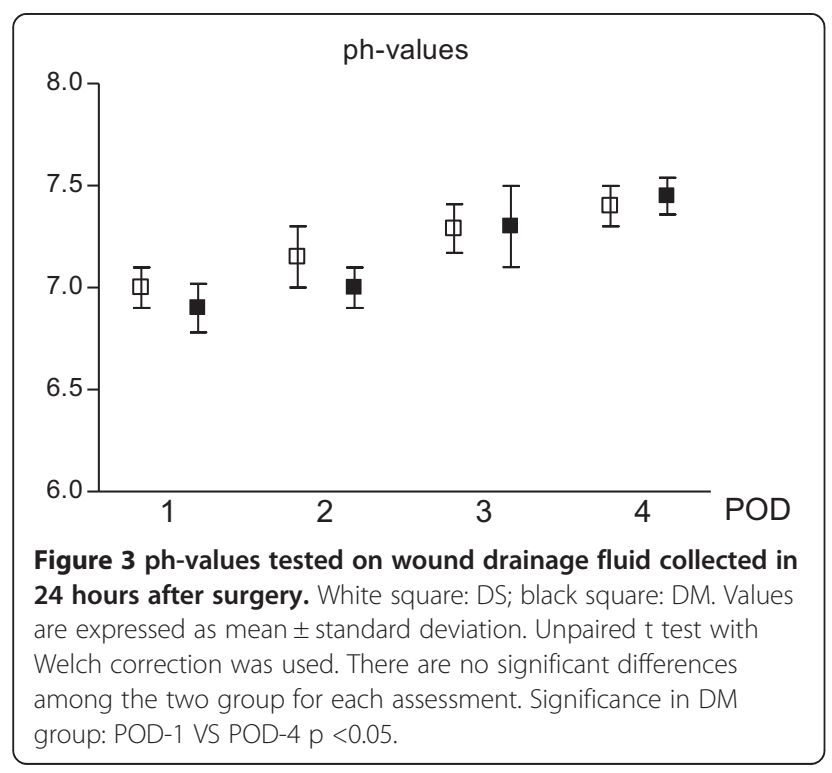

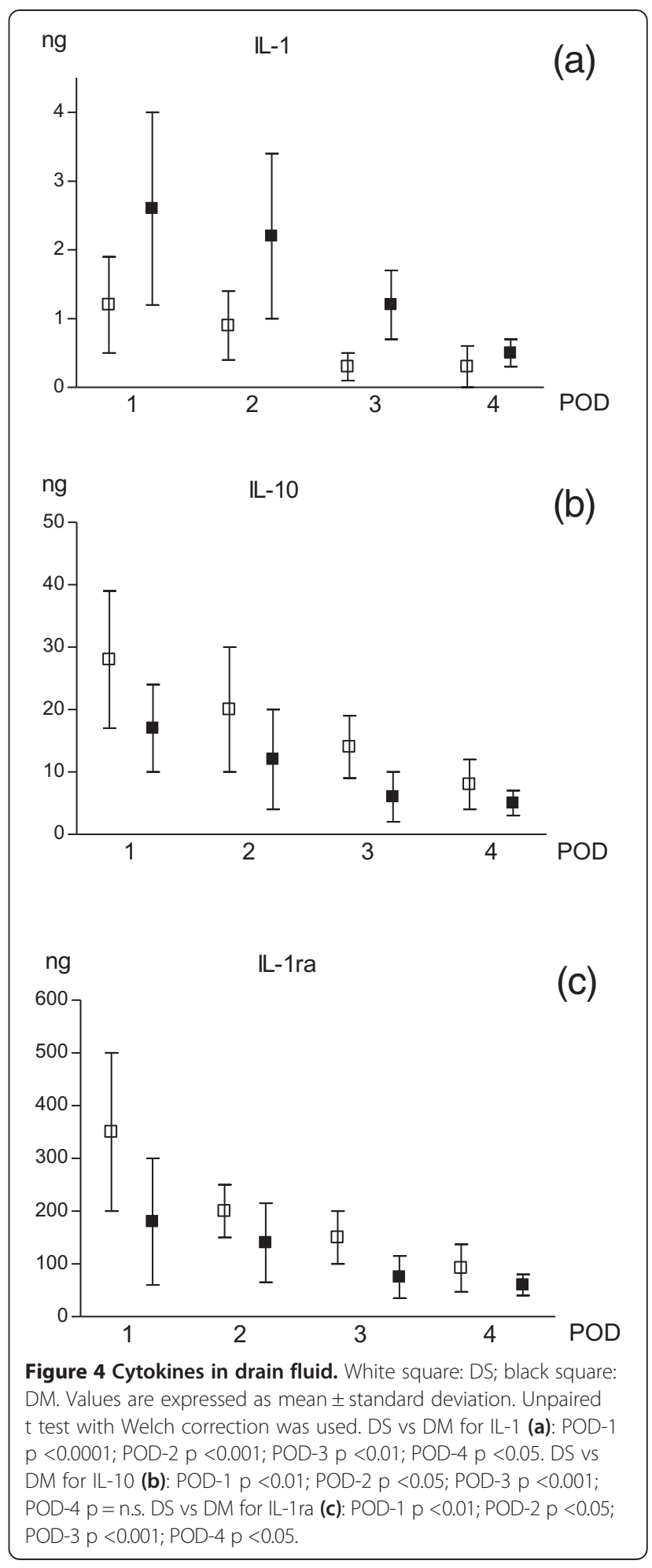

migration of monocytes/macrophages at the implant site with the release of cytokines, chemokines, growth and angiogenic factors etc.

Biomaterials immediately and spontaneously acquire a layer of host proteins prior to interacting with host cells. 
Thus it is highly probable that the types, levels, and surface conformations of the adsorbed proteins are critical determinants of the tissue reaction to such implants [10]. Conversely, the types, concentrations, and conformations of these surface-adsorbed proteins are dependent on biomaterial surface properties that dictate adhesion and survival of cells, especially monocytes and macrophages, on protein-coated surfaces [11].

The interaction of adsorbed proteins with adhesion receptors present on inflammatory cell populations, constitutes the major cellular recognition system for implantable synthetic materials. The presence of adsorbed proteins such as albumin, fibrinogen, complement, fibronectin, vitronectin, $\gamma$ globulin and others, modulate host inflammatory cell interactions and adhesion and thus are linked to subsequent inflammatory and wound healing responses [12,13].

The acute inflammatory response with biomaterials usually resolves quickly, in less than one week, depending on the extent of injury at the implant site. If present high levels and especially for prolonged periods of time may have a detrimental effect on healing [14].

The evaluation of some inflammatory response markers, in the drained fluid, allows us to better assess the events that follow a surgical wound [15]. However, the presence of a drain can itself modify the profiles of cytokines and wound healing. On the other hand, the levels of cytokines secreated near the surgical wound can be determined only by using the drainage, because the study of drain fluid is still the best clinical surrogate marker of healing [15]. Knowing the dynamic and the secretion profiles of different factors involved in the wound healing process at the site of surgical operation seems to be important because these soluble mediators play a crucial role in the pathophysiology of wound healing, as well as being popular target in the modification of the repair response [16].

This study shows that the inflammatory reaction differs in the subcutaneous and in the near-prosthetic space. High levels of anti-inflammatory interleukins (IL-10 and IL-1ra), and low levels of pro-inflammatory interleukin (IL-1) and CRP were detected in the DS fluid. Contrarily, in the DM fluid a low levels of anti-inflammatory interleukins and high levels of pro-inflammatory interleukin (IL-1) were observed.

In the DM fluid the elevated levels of pro-inflammatory cytokines promoted both a systemic and local inflammatory response directly or indirectly, causing fibro-proliferative lesions and maintaining inflammatory reaction and tissue scaring [17]. On the contrary, the higher IL-1ra and IL-10 production in DS fluid indicates that the inflammatory response is attenuated by the inhibitory activity of these anti-inflammatory cytokines [18-20]. The early production of IL-1, followed by its decrease by post-operative day, is in line with the essential role of this cytokine in the healing process because it increases collagen synthesis and stimulates keratinocytes and fibroblast growth [21].

Some studies indicate that a more intense acute inflammatory response determines the formation of strong scar tissue. Marois et al. [22] observed that a more intense inflammatory reaction early after implantation, stimulates significantly greater tissue in-growth and integration. Junge et al. [23] observed in experimental study on animal model after implantation of mesh, that the lesser degree of reaction was followed by less connective tissue formation and a higher partial volume of fat tissue.

It has been commonly observed in clinical practice of the patients, who previously underwent prosthetic incisional hernia repair with sublay technique, that the preparation of subcutaneous space results more easy and feasible with respect to the dissection of the space where there is the mesh, because in this case a strong scar tissue is represented.

The incidence of seroma after incisional hernia repair is high, reaching values of 3\% [24]. The reasons for this are not known, however, high BMI, lowered preoperative serum concentration of total protein and albumin and high serum concentration of IL-1-RA are related to an elevated risk for postoperative seroma formation [24]. In this study, the small number of patients studied and the absence of seroma does not allow us to correlate the inflammatory response and the amount of fluid drained with the development of seroma. A significant reduction of $\mathrm{pH}$ values was detected in DM fluid only on POD-4. The $\mathrm{pH}$ value within the wound-milieu indirectly and directly influences all biochemical reactions which take place in the healing process. It could be proven that wound healing is correlated to wound $\mathrm{pH}$ changes, as they can lead to an inhibition of endogenous enzymes [25,26], such as an inactivation of fibroblast bindering its wound healing activity [27]. For more than three decades the common assumption amongst physicians was that a low $\mathrm{pH}$ value, as found in normal skin, is favorable for wound healing. Recent investigation showed that the wound $\mathrm{pH}$ is indeed potent influential factor in the healing process [26]. A significant reduction in $\mathrm{pH}$ is associated with the formation of seroma [28] and the stabilization of the $\mathrm{pH}$ values can reduce the adverse tissue reaction [29].

\section{Conclusions}

In conclusion, our data showed that an acute inflammatory reaction is present in both sites examined; however, in the site after mesh implantation it was significantly higher.

\section{Abbreviations}

DM: Drain over Mesh; DS: Subcutaneous Drain; IL: Interleukin; CRP: C-Reactive Protein; POD: Post-Operative Day. 


\section{Competing interests}

No competing financial interests exist. The corresponding author had full access to all the data in the study and takes responsibility for the integrity of the data and the accuracy of the data analysis.

\section{Authors' contributions}

$\mathrm{RP}$ contributes to writing the manuscript, analysis and interpretation of the data; AC was envolved in drafting the manuscript and critical revision; PA was envolved in the acquisition, analysis and interpretation of data and collaborated in writing the manuscript; GA contributed in the acquisition and analysis of data; SB contributed to the acquisition and analysis of data; GD performed the surgical treatment envolved in the conception and design of the manuscript, final approvation of the manuscript. All authors have read and approval the final manuscript.

\section{Acknowledgements}

This work was supported by grants from the Italian Ministry of Education, University and Research, ex60\% to Gaetano Di Vita. Sources of funding were given only to Gaetano Di Vita and were used for the purchase of supplies. We thank the technicians of the laboratory analysis of the "Azienda Ospedaliera Universitaria Policlinico Paolo Giaccone dell'Università degli Studi di Palermo" for the determination of the various parameters. We thank Piero Almasio who provided statistical analysis services. Authors obtained permission to acknowledge from all those mentioned in the Acknowledgements section.

Received: 7 March 2014 Accepted: 17 October 2014 Published: 15 November 2014

\section{References}

1. Shin D, Lipshultz LI, Goldstein M, Barmé GA, Fuchs EF, Nagler HM, McCallum SW, Niederberger CS, Schoor RA, Brugh VM 3rd, Honig SC: Herniorrhaphy with polypropylene mesh causing inguinal vasal obstruction: a preventable cause of obstructive azoospermia. Ann Surg 2005, 241(4):553-558.

2. Legrand $M$, Klijn $E$, Payen $D$, Ince $C$ : The response of the host microcirculation to bacterial sepsis: does the pathogen matter? J Mol Med 2010, 88(2):127-133.

3. Klinge U, Klosterhalfen B, Birkenhauer V, Junge K, Conze J, Schumpelick V: Impact of polymer pore size on the interface scar formation in a rat model. J Surg Res 2002, 103(2):208-214.

4. Asarias JR, Nguyen PT, Mings JR, Gehrich AP, Pierce LM: Influence of mesh materials on the expression of mediators involved in wound healing. J Invest Surg 2011, 24(2):87-98.

5. Pascual G, Rodríguez M, Sotomayor S, Pérez-Köhler B, Bellón JM: Inflammatory reaction and neotissue maturation in the early host tissue incorporation of polypropylene prostheses. Hernia 2012, 16(6):697-707.

6. Schumpelick V, Klinge U, Junge K, Stumpf M: Incisional abdominal hernia: the open mesh repair. Langenbecks Arch Surg 2004, 389(1):1-5.

7. Polverini PJ, Cotran PS, Gimbrone MA Jr, Unanue ER: Activated macrophages induce vascular proliferation. Nature 1977, 269(5631):804-806.

8. Hunt TK, Knighton DR, Thakral KK, Goodson WH 3rd, Andrews WS: Studies on inflammations and wound healing: angiogenesis and collagen synthesis stimulated in vivo by resident and activated wound macrophages. Surgery 1984, 96(1):48-54.

9. Anderson JM, Rodriguez A, Chang DT: Foreign body reaction to biomaterials. Semin Immunol 2008, 20(2):86-100.

10. Wilson CJ, Clegg RE, Leavesley DI, Pearcy MJ: Mediation of biomaterial-cell interactions by adsorbed proteins: a review. Tissue Eng 2005, 11(1-2):1-18.

11. Anderson JM: Biological responses to materials. Annu Rev Mater Res 2001, 31:81-110.

12. Jenney $C R$, Anderson JM: Adsorbed serum proteins responsible for surface dependent human macrophage behaviour. J Biomed Mater Res 2000, 49(4):435-437

13. Brodbeck WG, Colton E, Anderson JM: Effects of adsorbed heat labile serum proteins and fibrinogen on adhesion and apoptosis of monocytes/macrophages on biomaterials. J Mater Sci Mater Med 2003, 14(2):671-675

14. Barrientos S, Stojadinovic O, Golinko MS, Brem H, Tomic-Canic M: Growth factors and cytokines in wound healing. Wound Rep Reg 2008, 16(5):585-601.
15. Baker EA, Gaddal SE, Aitken DG, Leaper DJ: Growth factor profiles in intraperitoneal drainage fluid following colorectal surgery: relationship to wound healing and surgery. Wound Rep Reg 2003, 11(4):261-267.

16. Klinge $U$, Theuer $S$, Krott E, Fiebeler A: Absence of circulating aldosterone attenuates foreign body reaction around surgical sutures. Langenbecks Arch Surg 2010, 395(4):429-435.

17. Murphy JE, Robert C, Kupper TS: Interleukin-1 and cutaneous inflammation: a crucial link between innate and acquired immunity. J Invest Dermatol 2000, 114(3):602-608.

18. Dinnarello CA: Interleukin-1 beta, interleukin-18, and the interleukin-1 beta converting enzyme. Ann NY Acad Sci 1998, 856:1-11.

19. Arend WP, Malyak M, Guthridge CS, Gabay C: Interleukin-1 receptor antagonist: role in biology. Annu Rev Immunol 1998, 16:27-55.

20. Azouz A, Razzaque MS, El-Hallack M, Taguchi T: Immunoinflammatory responses and fibrinogenesis. Med Electron Microsc 2004, 37(3):141-148.

21. Sauder DN, Kilian PL, McLane JA, Quick TW, Jakubovic H, Davis SC, Eaglstein WH, Mertz PM: Interleukin-1 enhances epidermal wound healing. Lymphokine Res 1990, 9(4):465-473.

22. Marois Y, Cadi R, Gourdon J, Fatouraee N, King MW, Zhang Z, Guidoin R: Biostability, inflammatory response, and healing characteristics of a fluoropassivated polyesterknit mesh in the repair of experimental abdominal hernias. Artif Organs 2000, 24(7):533-543.

23. Junge $K$, Klinge $U$, Klosterhalfen B, Mertens PR, Rosch R, Schachtrupp A, Ulmer F, Schumpelick $V$ : Influence of mesh materials on collagen deposition in a rat model. J Invest Surg 2002, 15(6):319-328.

24. Klink CD, Binnebösel M, Lucas AH, Schachtrupp A Grommes J, Conze J, Klinge $U$, Neumann $U$, Junge K: Serum analyses for protein, albumin and IL-1-RA serve as reliable predictors for seroma formation after incisional hernia repair. Hernia 2011, 15(1):69-73.

25. Schreml S, Szeimies RM, Karrer S, Heinlin J, Landthaler M, Babilas P: The impact of the ph value on skin integrity and cutaneous wound healing. J Eur Acad Dermatol Venereol 2010, 24(4):373-378.

26. Schneider LA, Korber A, Grabbe S, Dissemond J: Influence of ph on wound-healing: a new perspective for wound-therapy? Arch Dermatol Res 2007, 298(9):413-420.

27. Pineda-Lucena A, Núñez De Castro I, Lozano RM, Muñoz-Willery I, Zazo M, Giménez-Gallego G: Effect of low ph and heparin on the structure of acidic fibroblast growth factor. Eur J Biochem 1994, 222(2):425-431.

28. Klink CD, Binnebösel M, Lucas AH, Schachtrupp A, Klinge U, Schumpelick V, Junge K: Do drainage liquid characteristics serve as predictors for seroma formation after incisional hernia repair? Hernia 2010, 14(2):175-179.

29. Heidemann W, Jeschkeit-Schubbert S, Ruffieux K, Fischer JH, Jung H, Krueger $G$, Wintermantel E, Gerlach KL: pH-stabilization of predegraded PDLLA by an admixture of water-soluble sodiumhydrogenphosphate-results of an in vitro- and in vivo-study. Biomaterials 2002, 23(17):3567-3574.

doi:10.1186/1471-2482-14-91

Cite this article as: Patti et al:: Acute inflammatory response in the subcutaneous versus periprosthethic space after incisional hernia repair: an original article. BMC Surgery 2014 14:91.

\section{Submit your next manuscript to BioMed Central and take full advantage of:}

- Convenient online submission

- Thorough peer review

- No space constraints or color figure charges

- Immediate publication on acceptance

- Inclusion in PubMed, CAS, Scopus and Google Scholar

- Research which is freely available for redistribution 